\title{
AN UPDATED INSECT EXCLOSURE DESIGN FOR POLLINATION ECOLOGY
}

\author{
Troy Tetreault* and Ken Aho
}

Idaho State University Department of Biological Sciences, 921 South 8th Ave., Stop 8007, Pocatello, ID 83209-8007

Journal of Pollination Ecology, 29(19), 2021, pp 249-257

DOI: $10.26786 / 1920-$

$7603(2021) 651$

Received 10 June 2020, accepted 20 August 2021 *Corresponding author: tetrtroy@isu.edu

\begin{abstract}
Exclosures are a common method for quantifying the effects of animal pollinators on flowering plant species. However, a lack of standardized designs or clear descriptions of previously implemented exclosure designs decreases replicability in pollination studies and reduces scientific rigor. We summarized previous descriptions of pollination exclosure designs, and developed/tested a novel exclosure design in alpine environments on the Beartooth Plateau in northern Wyoming, USA. This exclosure design consists of a cylindrical internal wire frame, integrated ground stakes, and various mesh materials attached to the exterior. Exclosures on the plateau showed high efficacy in inhibiting insects from pollinating flowering plants, and nearly all of these exclosures remained functional throughout the time they were in place. Our updated exclosure design is effective, inexpensive, easy to produce, and widely applicable across differing ecosystems and experimental design types.
\end{abstract}

Keywords-Pollination, ecology, insects, plants, conservation, exclosure

\section{INTRODUCTION}

Exclosures are a common method for quantifying the effects of animal pollinators on flowering plant species (Colwell \& Fuentes 1975; Macior, 1978; Lazaro et al. 2014). Terms used to describe devices preventing pollinator access to flowering plants include: "cage", "exclosure", "mesh", and/or "netting" (Peterson et al. 1960; Macior 1970; Macior 1973; Thorp \& Estes 1975; Larson \& Barrett 1999; Al-Kahtani et al. 2017). Use of these terms is generally unaccompanied by explicit descriptions of exclosure design. A lack of standardized designs or clear descriptions of pollinator exclosures decreases replicability in pollination studies and reduces scientific rigor (Hutson 1925; Kaufmann 1975).

Effective pollinator inhibition requires properly designed exclosures suitable for the particular conditions of the study system. Pollinator studies in the alpine zone are particularly challenging. In these systems, exclosures must be amenable to rocky slopes with shallow soils, and capable of withstanding inclement weather. One goal of this paper is to develop and describe pollinator exclosures adequate for alpine conditions. The reasons for this are twofold. First, exclosure designs suitable for the alpine are likely to be capable of weathering climatic extremes from most terrestrial systems. Second, studies of alpine pollination are particularly relevant given the negative effects of global warming on alpine plant species (Guisan \& Theurillat 2000; Ernakovich et al. 2014; Gobiet et al. 2014), including the increased likelihood of plant-pollinator phenological mistimings (Inouye 2008; Kudo 2021), the dependence of alpine plants on animal pollinators, particular hymenopterans (Bauer 1983; Ollerton et al. 2011; Pepin et al. 2015; Byers \& Cheng 2017; Inouye 2020), and the global decline of many hymenopteran pollinators (Sanchez-Bayo \& Wyckhuys 2019).

In our consideration of animal pollinator exclosures, we sought to complete two tasks. First, as a historical baseline, we wished to assemble and summarize previous descriptions of pollination exclosures. Second, we wanted to develop and test an exclosure design that was: 1) adequate for inclement conditions, 2) effective as an exclosure mechanism, including the exclusion of pollinators of particular size ranges, 3) lightweight and durable, 4) easy to produce and 5) cost-effective.

\section{HISTORICAL ANIMAL POLLINATOR EXCLOSURE DESIGNS}

A number of papers have reported the use of exclosures in pollinator research. Most of these, 
however, provide poor guidance for reproducing exclosure designs, or have been criticized as inadequate for measuring pollinator effects. Papers using pollinator exclosures often mention the use of fabric bags of varying mesh sizes that are either draped over a plant or particular inflorescences to prevent pollination (Fig 1A; Graham \& Jones 1996; Khan et al. 2012; Kings \& Sargent 2012). Other papers use meat casing material or fiberglass mesh to enclose flowers at a small scale (Whitney 1984). These designs can be criticized for three reasons. First, they may fail to exclude animal pollinators or encourage selfpollination in non-obligate out-crossing plants because of the absence of structural support that prevents materials from touching the flower. Second, attachment design for these exclosures may come loose, failing to exclude insects (Delaplane et al. 2015), and the small size of exclosure may lead to failure under windy conditions. Third, attachment of exclosures may damage plants, hampering inferences concerning pollinator effects (Orueta 2002). An improvement to bag-exclosure designs incorporates rigid supports that separate exclosure materials from flowers (Fig 1B; Young 1980; O'Brien 1980; Kalisz et al. 1999; Whitaker et al. 2007; Montgomery \& Phillips 2015; Cunningham-Minnick et al. 2019). Historically, exclosures with structural supports (excluding smaller devices) have been rectangular, infrequently anchored to the ground, and heavy (Fig 1C, D; Roberts \& Freeman 1908; Herrera 1987; Herrera 2000). These constraints, particularly weight, may prevent usage in inaccessible locations. On the other hand, lightweight designs may require an anchoring system to be persistent in windy ecosystems. Historically, anchors have consisted of wooden/metal stakes, with some designs utilizing a basal ring for supporting stakes (Arroyo et al. 2013; Pacheco 2016). While effective, these designs could be improved through the integration of anchoring components. Few studies have reported using cylindrical exclosures, even though this shape is amenable to the morphology of most plants (Bliss 1962; Wainwright 2013). Papers using cylindrical exclosures have not provided sufficient details to allow replicability (Abdala-Roberts et al. 2009; Abdala-Roberts et al 2014). Cone-shaped exclosures have been used but do not work well with hardware mesh (Allphin 2005).

Another topic of consideration for pollinator exclosures is their potential confounding effect on environmental factors. For instance, exclosures may affect surface soil moisture, stomatal conductance, total plant biomass, wind speed, solar radiation, and the availability of rainfall
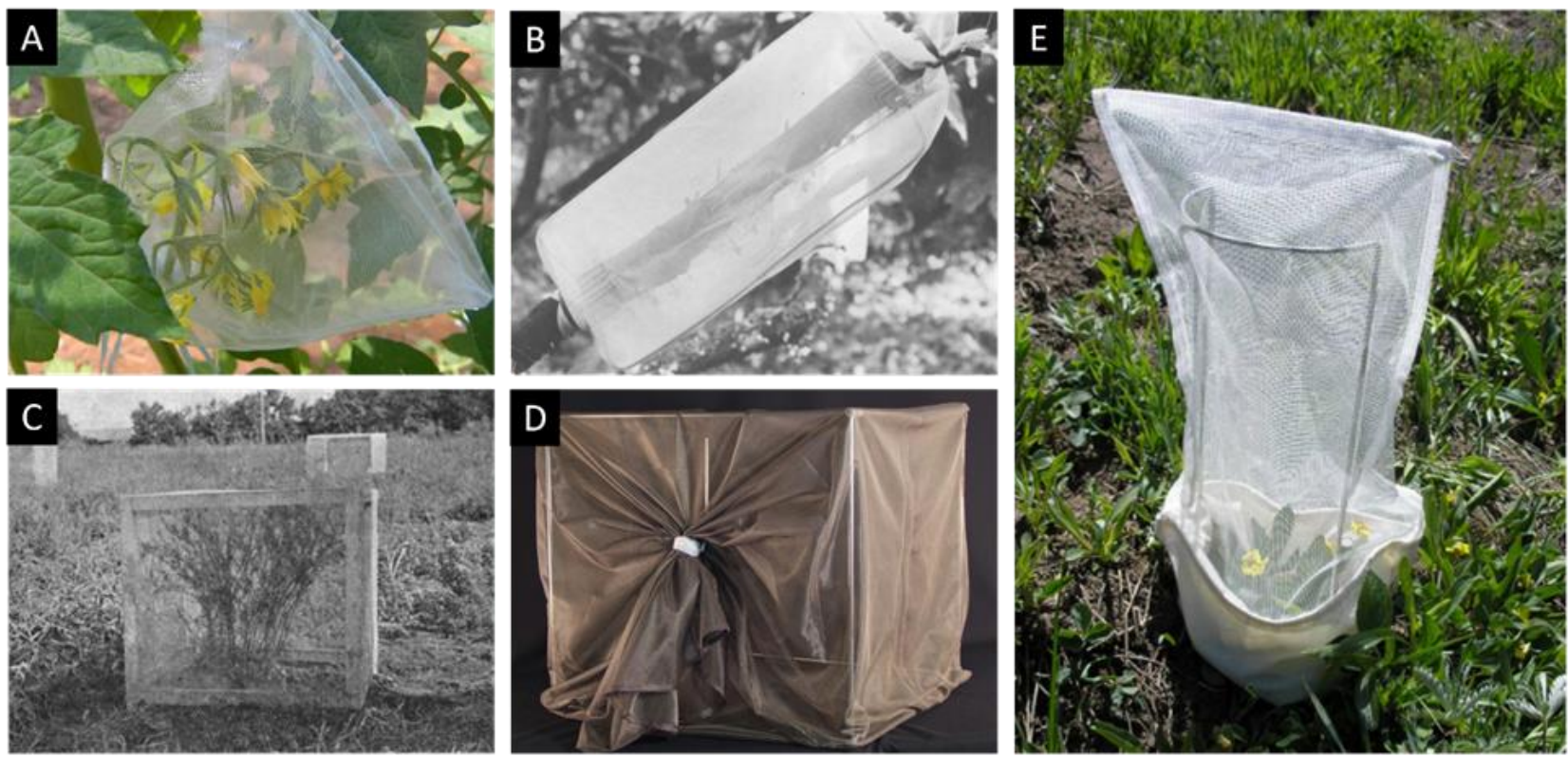

Figure 1. (A) Mesh exclosure around a plant without structural support (Dixon 2017) (B) Bag exclosure supported by wire (Young 1983) (C) Wooden-frame exclosures surrounding whole plant (Roberts \& Freeman 1908) (D) Metal-frame exclosure with mesh 
bag (BioQuip, Catalog \#1451D) (E) Mesh bag with weighted bottom and separate metal frame staked to the ground (Thomson et al. 2011)

(Hand \& Keaster 1967; Perillo et al. 2015). Other studies have reported no difference in these important environmental variables between exclosure and open sites (Lazaro et al. 2014). The effects of exclosures thus may be site specific and/or related to the materials used. Clearly, recognition of confounding effects is necessary when using exclosures for pollination experiments.

\section{A NOVEL POLLINATOR EXCLOSURE DESIGN}

Our design improves on existing structures through the use of lightweight rigid metal wire bent to conform to mesh constraints, and affixed to the ground using an integrated anchoring system (cf. Thomson et al. 2011). Thus, our approach eliminates the need for a basal support to hold stakes and is modifiable for uneven terrain. Inspiration for our design comes largely from Kearns and Inouye (1993) who mention the use of tomato cages as support for net bags to exclude pollinators. The structure is also compatible with any mesh bag types, including rigid hardware cloth.

\section{MATERIALS AND METHODS}

\section{EXCLOSURE ASSEMBLY}

The internal structure of the exclosure consists of wire fencing material, which comes in cylindrical rolls (Everbilt, 14-gauge galvanized steel wire, $5 \times 10 \mathrm{~cm}$ opening). Wire cutters were used to cut the 14-gauge wire fencing to desired length. Fencing was cut to the vertical wires for attachment of the loose ends with zip ties (Commercial Electric, $2.54 \mathrm{~cm}$, UL type 21, standard nylon) (Fig. 2A). For an incorporated anchoring system, we cut the bottom-most horizontal support so that vertical wires remained (Fig. 2B). When rocky soils prevent insertion of wire extensions, extensions can be twisted and bent parallel to the surface, and the frame can be affixed to the ground using U-nails (Fas'n'Tite fencing staples, galvanized, $4.45 \mathrm{~cm}, 9$ gauge) (Fig. 2C). U-nail size can be changed depending on soil conditions.

The exclosure frame can be used with a variety of mesh materials, including hardware cloth (Fig. 3). We cut hardware cloth (Everbilt, 19-gauge, galvanized steel wire, $1.27 \mathrm{~cm}$ mesh opening) with metal shears lengthwise, to the correct height of
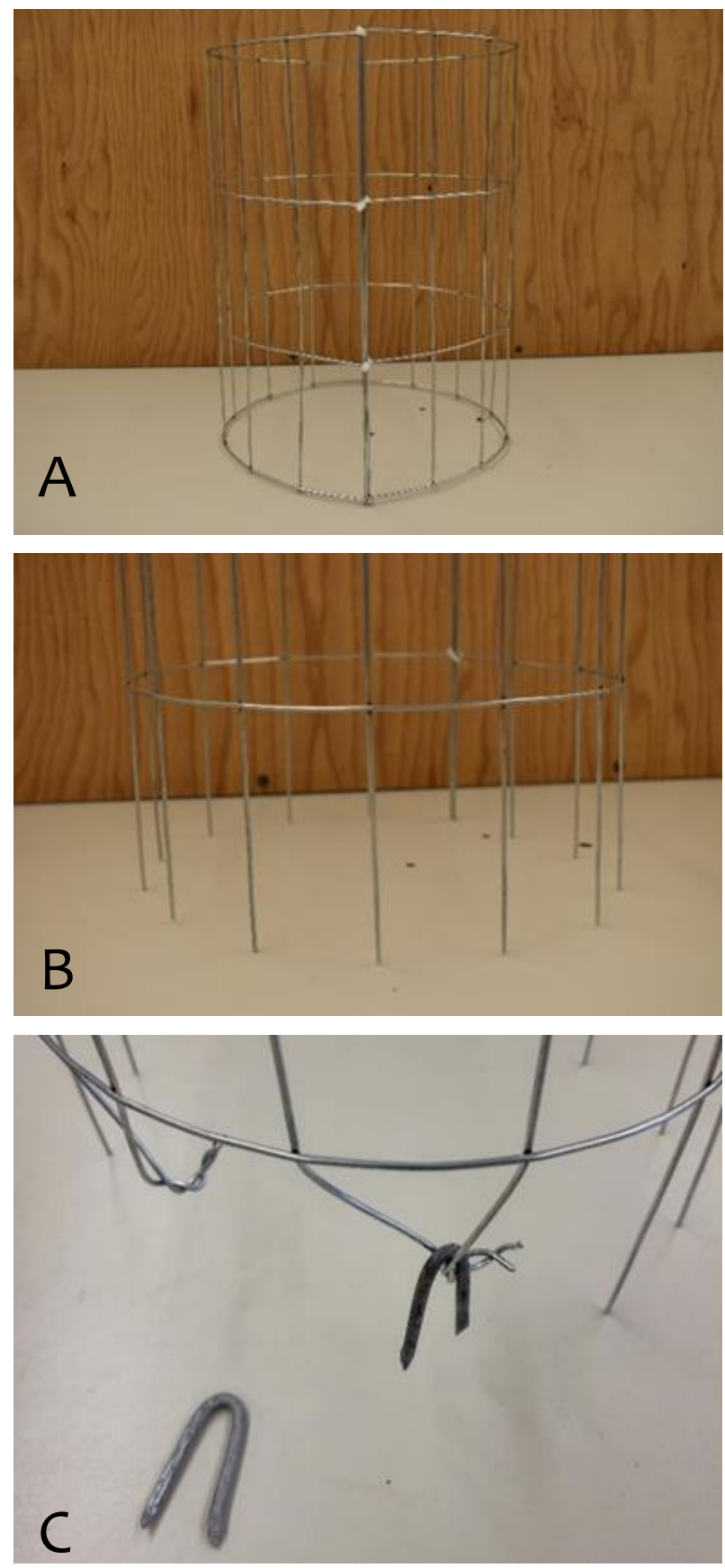

Figure 2. Exclosure frame, without any external mesh covering. (A) Exclosure frame assembled with zip ties, (B) Exclosures bottom horizontal support cut for integrated stakes, (C) in the case of hard ground, use of fencing staples may be necessary.

the exclosure (Fig. 3A). Hardware cloth was attached with small zip ties (Fig. 3B). To make the lid, we cut a square of hardware cloth slightly larger than the diameter of the exclosure opening. 
We attached the square section to the top of the exclosure, cut off excess, and attached with zip ties (Fig. 3C).
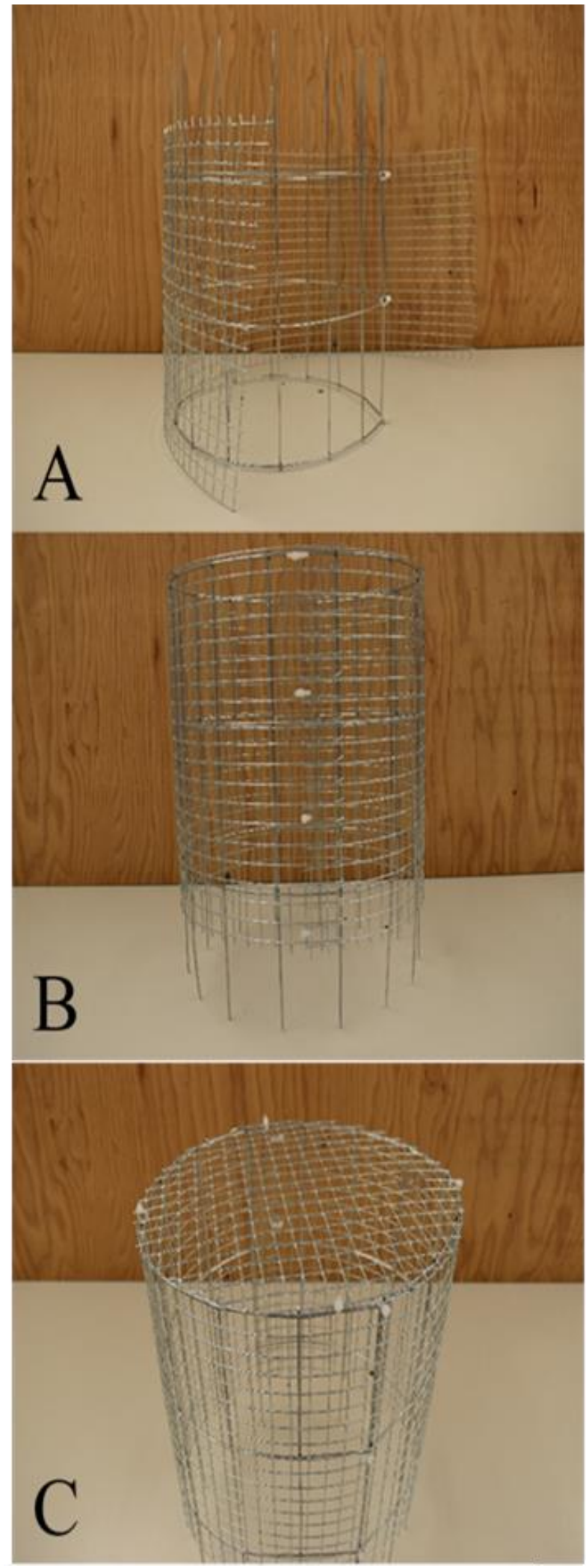

Figure 3. Attachment of hardware cloth to internal frame structure. (A) Completed exlosure frame with hardware cloth unattached, (B) Hardware cloth attached to the side of exclosure, (C) Hardware cloth attached to the top of exclosure.

Material with different sized openings can be used to exclude pollinators of specific size. Fig 4. shows an exclosure with screen-door mesh (Phifer, silver-grey, fiberglass screen, $1 \times 1 \mathrm{~mm}$ opening), to exclude all pollinators. Pre-made pollination bags can be used to fit over the internal exclosure structure. For example, a pollination bag designed by Thomson et al. (2011) could be employed that would eliminate production time and the need to fill gaps with native materials (i.e., soil, rock). While straightforward to assemble, this option is less cost effective.

\section{FIELD TESTING}

We field-tested exclosures at $3050 \mathrm{~m}$ elevation on the Beartooth Plateau, Wyoming, US during the summer of 2020. This alpine environment is characterized by vast summit plateaus and harsh weather conditions. One hundred and twentythree pollinator exclosures were randomly placed within six blocks along an elevational gradient.

Three types of exclosures (control, wire-mesh, and fine-mesh) were randomly placed within each block for individuals of each of seven flowering herbaceous alpine species (Castilleja pulchella, Delphinium bicolor, Lupinus monticola, Mertensia alpina, Oxytropis campestris, Polemonium viscosum, Trifolium dasyphlorum). One-hundred and twentythree exclosures were placed instead of $7 \times 6 \times 3=$ 126 exclosures because $D$. bicolor occurred at only five of the six elevational blocks.

Control exclosures were mesh-free and designed without a cap, while wire mesh and fine mesh exclosures meant to exclude insects were completely wrapped. The exclosures remained on the Beartooth Plateau from July $7^{\text {th }}$ to August 29th, and monitored daily ( $>5 x /$ week) for defects or failures. Average height of exclosures was $50 \mathrm{~cm}$, which was excessive for the growth form of plants on the plateau. We also measured soil moisture (volumetric water content) and temperature within and outside of 54 exclosures. At the end of the experimental period fruit set was recorded, and a mixed-effect ANOVA was used to analyze fruit set differences between exclosure types, plant species, and the interaction of exclosure types and 
plant species. A paired $t$-test was used to test for soil moisture and temperature differences for paired inside/outside exclosure measurements.

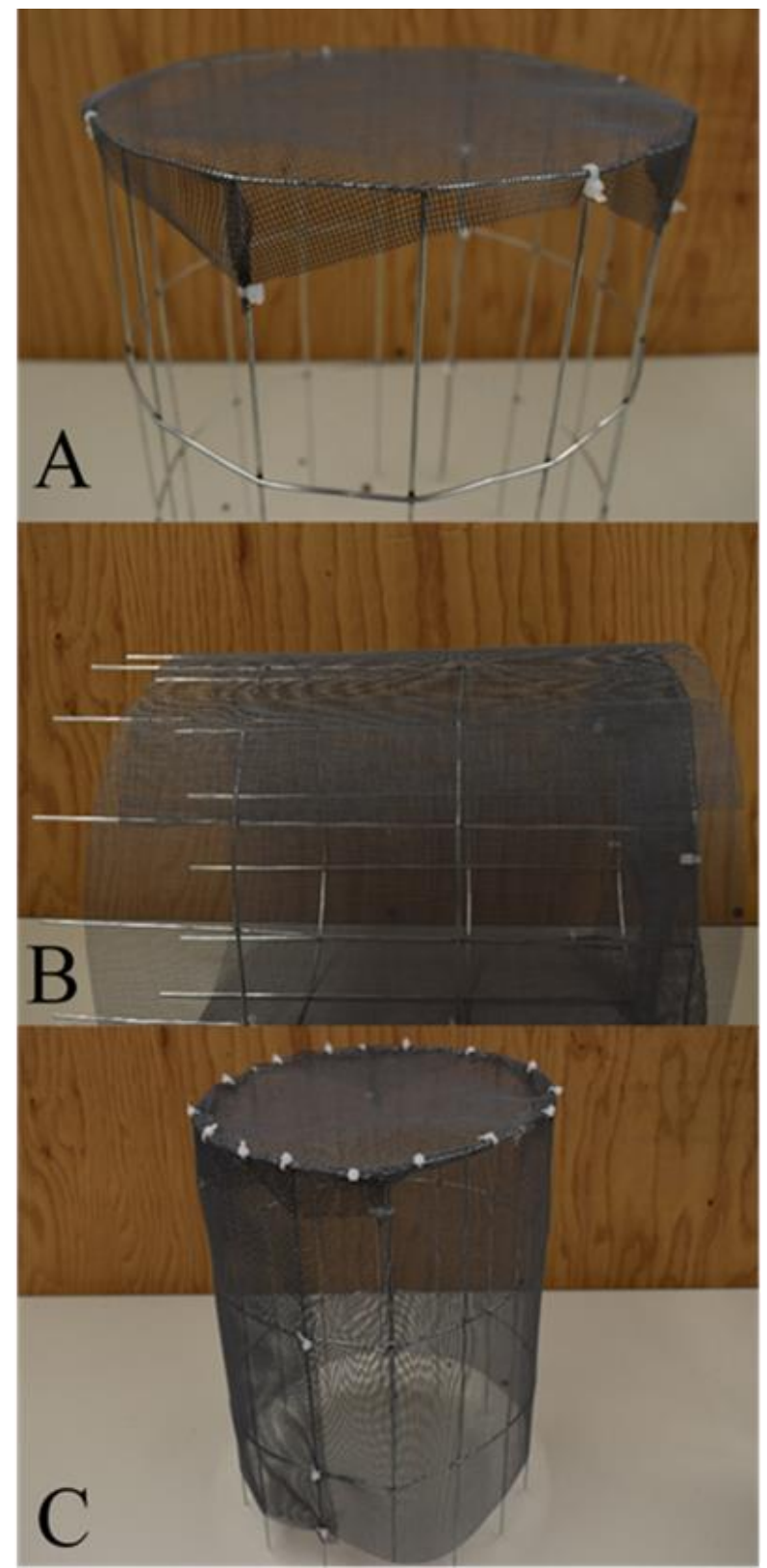

Figure 4. Attachment of screen door mesh to internal frame structure. (A) Mesh attached to the top of exclosure, (B) Mesh surrounding the side of exclosure, showing length needed for attachment, (C) Mesh attached securely to exclosure.

\section{RESULTS AND DISCUSSION}

Mesh exclosures demonstrated high efficacy in inhibiting insects from reaching flowering plants, with plants fruiting at a low level while in noncontrol exclosures. A mixed-effect ANOVA identified significant $(\alpha=0.05)$ differences in fruit set based on exclosure type (control, wire-mesh, and fine-mesh) $\left(F_{2,101}=3.9103, P=0.023\right.$, Fig. 5$)$ and species $\left(F_{6,101}=27.5, P<2 \times 10^{-16}\right)$. No pollinators were observed entering or leaving non-control exclosures (Tetreault, personal observations). No exclosure $\times$ species interaction and random blocking (elevational) effects were detected, ( $F_{12,101}$ $=27.5, P=0.635)$ and $\left(\chi^{2}=-1.421 \mathrm{e}^{-13}, P=1\right)$, respectively, in the mixed effect model.

In post hoc exclosure comparisons, fruit set from the fine mesh exclosures was significantly different than the control after controlling for familywise type I error (FWER) using Tukey's HSD (adjusted$P=0.018846$; Fig 5). Baseline fruit set was species specific. In twelve of twenty-one possible post hoc pairwise comparisons, fruit set among species was significantly different after controlling for FWER (Fig. 6).

No significant differences were found between exclosures and open sites for soil temperature $\left(t_{53}=\right.$ $0, P=1)$, although a trend was apparent for soil moisture $\left(t_{53}=-2.0018 . P=0.05044\right)$. Thus, we recommend that future studies measure inside/outside exclosure soil moisture to account for the potential confounding effect of exclosures on soil moisture.

Of the 120 exclosures distributed across the field site, 114 remained in place through the season. Of the six exclosure failures, five were covered with screen-door mesh. The smalleropening screen door mesh exclosures were more affected by wind. To mitigate these effects, we propose the following steps. To decrease wind exposure, we recommend that exclosure heights are minimized with respect to enclosed plants. To affix exclosures more firmly to the ground, exclosure lids can be weighted, and the anchoring mechanism can be reinforced with U-shaped stakes/fencing nails (Fig. 2C).

The high persistence rate of hardware cloth exclosures in the high wind conditions of the Beartooth Plateau bodes well for the use of this design in other ecosystems. The internal wire structure is the major advancement in our design over earlier designs. The wireframe is easy to attach to any hardware cloth gage for use in a variety of pollination experiments. The rigid structure allows for use of our design in exclosure 
studies involving larger herbivores (e.g., mice, small ungulates). Separate anchoring devices are generally not necessary because of the integrated
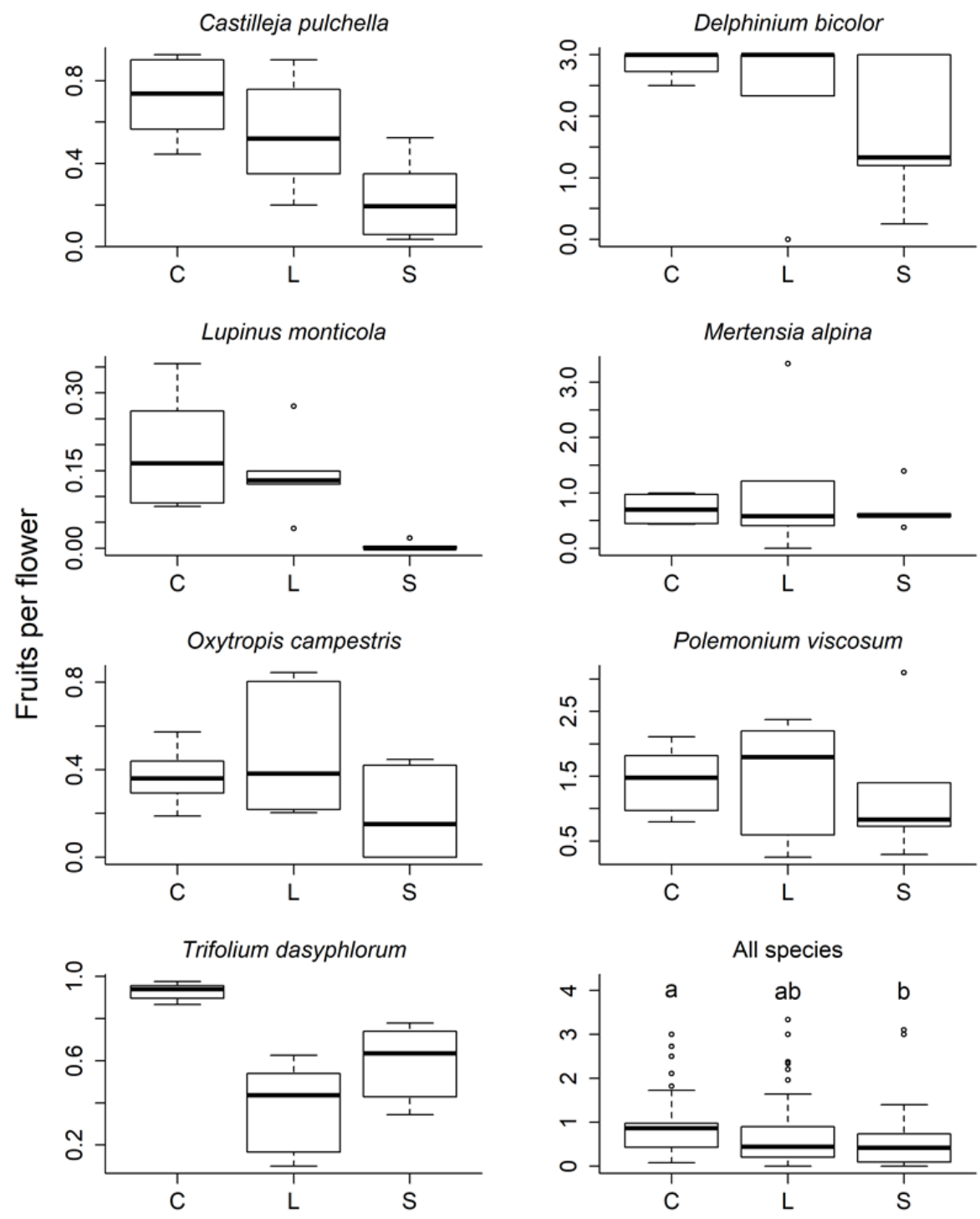

Figure 5. Fruits per flower by exclosure treatment. $\mathrm{C}=$ Control, $\mathrm{L}=$ Large wire mesh, $\mathrm{S}$ = fine screen door mesh. Widened central lines in boxes are medians. Hinges are quartiles. Whiskers extend to the most extreme data point that is no more than $\mathbf{1 . 5}$ times the length of the box away from the box. Lower right plot indicates differences between exclosure types for all species. Box plots with the same letter code indicates no significant difference in fruit set after controlling for FWER using Tukey's HSD. between the exclosure mesh and the ground surface. The combination of cost-effective materials, ease of production, high success rate in harsh conditions, and applicability across ecosystem and experimental design types should make this exclosure exceptionally useful for pollination ecology.

\section{ACKNOWLEDGEMENTS}

We would like to thank Dr. Joshua Grinath for providing feedback throughout the duration of this project, and Arya Legg, Maya Elliot and Lauren Stidham for help in the field. This work was funded by grants from the Idaho State Center for Ecological Research and Education, and the Biological Sciences Research
Committee. Thanks also to Dr. David Inouye and two anonymous reviewers for their useful comments.

\section{REFERENCES}

Abdala-Roberts L, Marrufo-Zapata D, Arceo-Gómez G, Parra-Tabla V (2014) Pollen limitation, fruit abortion, and autonomous selfing in three populations of the perennial herb Ruellia nudiflora. Plant Species Biology 29:25-33. https://doi.org/10.1111/j.1442-1984.2012. 00392.x

Abdala-Roberts L, Parra-Tabla V, Salinas-Peba L, Herrera CM (2009) Noncorrelated effects of seed predation and pollination on the perennial herb Ruellia nudiflora remain spatially consistent: Seed Predation and Pollination in R. nudiflora. Biological Journal of the 
Linnean Society 96:800-807. https://doi.org/10.1111/ j.1095-8312.2008.01170.x

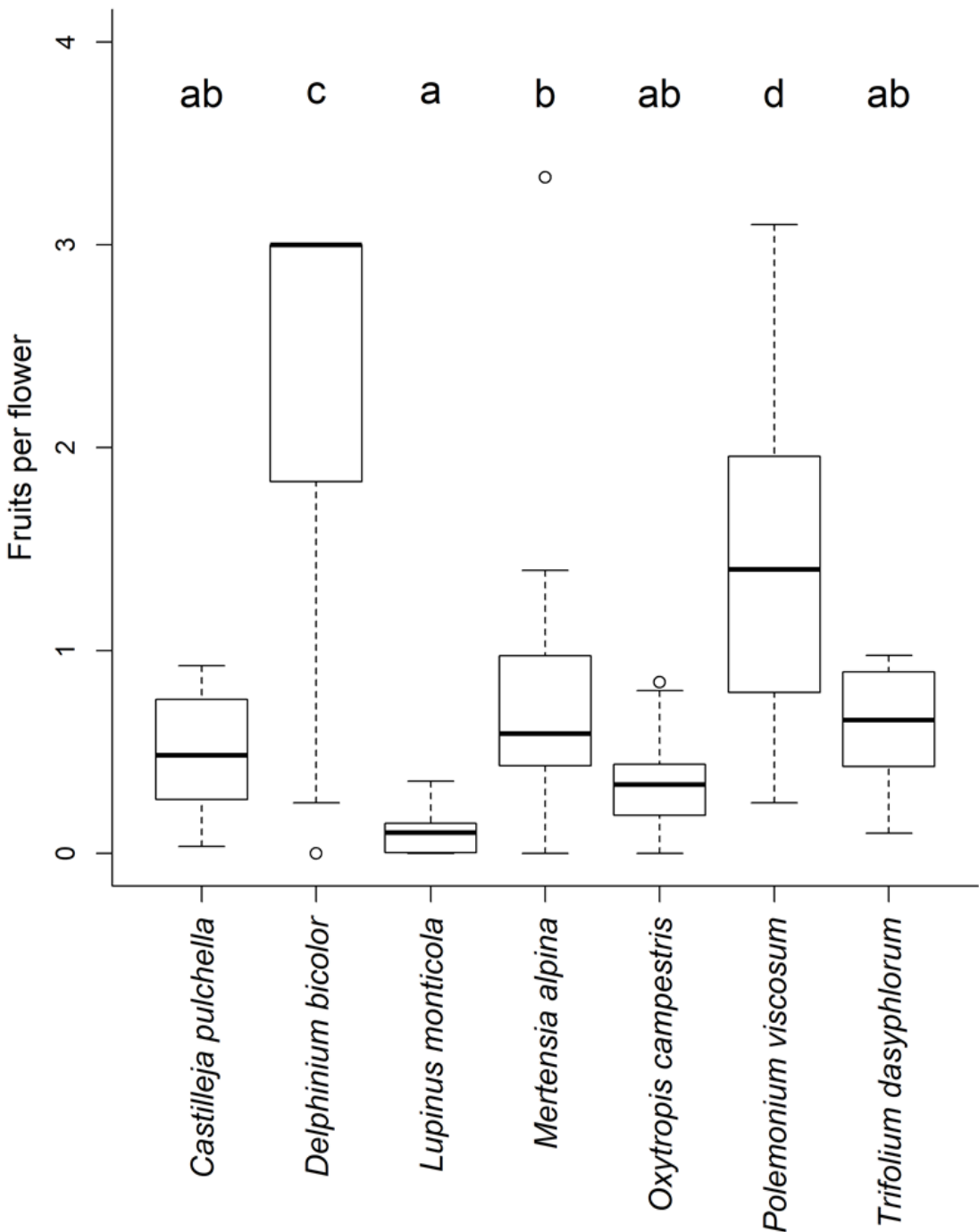

Al-Kahtani SN, Taha E-KA, Al-Abdulsalam M (2017) Alfalfa (Medicago sativa L.) seed yield in relation to phosphorus fertilization and honeybee pollination.
Figure 6. Fruit set per flower by plant species. See Fig. 5 for additional details on box and whisker plot components. Box plots with the same letter code indicate no significant difference in fruit set after controlling FWER using Tukey's HSD. For further plot information see Fig 5 caption.
Saudi J Biol Sci 24:1051-1055. https://doi.org/10.1016/ j.sjbs.2016.12.009

Allphin L, Brian N, Matheson T (2005) Reproductive success and genetic divergence among varieties of the rare and endangered Astragalus cremnophylax (Fabaceae) from Arizona, USA. Conservation Genetics 6:803-821. https://doi.org/10.1007/s10592-005-9039-z

Arroyo MTK, Dudley LS, Jespersen G, et al (2013) Temperature-driven flower longevity in a high-alpine species of Oxalis influences reproductive assurance. New Phytologist 200:1260-1268. https://doi.org/ 10.1111/nph.12443

Bauer PJ (1983) Bumblebee Pollination Relationships on the Beartooth Plateau Tundra of Southern Montana. American Journal of Botany 70:134-144. https://doi.org/10.2307/2443213

Bliss LC (1962) Adaptations of Arctic and Alpine Plants to Environmental Conditions. Arctic 15:117-144
Byers DL, Chang S-M (2017) Studying plant-pollinator interactions facing climate change and changing environments1. Appled Plant Science 5: https://doi.org/10.3732/apps.1700052

Colwell RK, Fuentes ER (1975) Experimental Studies of the Niche. Annual Review of Ecology and Systematics 6:281-310. https://doi.org/10.1146/annurev.es.06. 110175.001433

Cunningham-Minnick MJ, Peters VE, Crist TO (2019) Nesting habitat enhancement for wild bees within soybean fields increases crop production. Apidologie 50:833-844. https://doi.org/10.1007/s13592-019-00691-y

Delaplane KS, Dag A, Danka RG, et al (2013) Standard methods for pollination research with Apis mellifera. Journal of Apicultural Research 52:1-28. https://doi.org/10.3896/IBRA.1.52.4.12

Ernakovich JG, Hopping KA, Berdanier AB, et al (2014) Predicted responses of arctic and alpine ecosystems to 
altered seasonality under climate change. Global Change Biology 20:3256-3269. https://doi.org/10.1111 Lgcb.12568

Gobiet A, Kotlarski S, Beniston M, et al (2014) 21st century climate change in the European Alps-A review. Science of The Total Environment 493:1138 1151. https://doi.org/10.1016/j.scitotenv.2013.07.050

Graham L, Jones KN (1996) Resource Partitioning and Per-flower Foraging Efficiency in Two Bumble Bee Species. The American Midland Naturalist 136:401406. https://doi.org/10.2307/2426743

Guisan A, Theurillat J-P (2000) Assessing alpine plant vulnerability to climate change: a modeling perspective. Integrated Assessment 1:307-320. https://doi.org/10.1023/A:1018912114948

Herrera CM (1987) Components of Pollinator "Quality": Comparative Analysis of a Diverse Insect Assemblage. Oikos 50:79-90. https://doi.org/10.2307/3565403

Herrera CM (2000) Flower-to-Seedling Consequences of Different Pollination Regimes in an Insect-Pollinated Shrub. Ecology 81:15-29. https://doi.org/10.1890/00129658(2000)081[0015:FTSCOD]2.0.CO;2

Hutson R (1925) The Honey bee as an Agent in the Pollination of Pears, Apples and Cranberries. Journal of Economic Entomology 18:387-391. https://doi.org/ $\underline{10.1093 / j e e / 18.2 .387}$

Inouye DW (2008) Effects of Climate Change on Phenology, Frost Damage, and Floral Abundance of Montane Wildflowers. Ecology 89:353-362. https://doi.org/10.1890/06-2128.1

Inouye DW (2020) Effects of climate change on alpine plants and their pollinators. Annals of the New York Academy of Sciences 1469:26-37. https://doi.org/ $\underline{10.1111 / \text { nyas. } 14104}$

Kalisz S, Vogler D, Fails B, et al (1999) The mechanism of delayed selfing in Collinsia verna (Scrophulariaceae). American Journal of Botany 86:1239-1247. https://doi.org/10.2307/2656771

Kaufmann T (1975) Ecology and Behavior of Cocoa Pollinating Ceratopogonidae in Ghana, W. Africa. Environmental Entomology 4:347-351. https://doi.org/10.1093/ee/4.2.347

Khan K, Ahmad K, Razzaq A, et al (2012) Pollination Effect of Honey Bees, Apis mellifera L. (Hymenoptera: Apidae) on Apple Fruit Development and its Weight. Persian Gulf Crop Protection 1:1-5

Kearns CA, Inouye DW (1993) Techniques for pollination biologists. University Press of Colorado, Niwot, Colorado, USA.

King VM, Sargent RD (2012) Presence of an invasive plant species alters pollinator visitation to a native. Biol Invasions 14:1809-1818. $\quad$ https://doi.org/10.1007/ $\underline{\text { s10530-012-0191-3 }}$
Larson BMH, Barrett SCH (1999) The pollination ecology of buzz-pollinated Rhexia virginica (Melastomataceae). American Journal of Botany 86:502-511. https:// doi.org/10.2307/2656811

Lázaro A, Lundgren R, Totland $\varnothing$ (2014) Experimental reduction of pollinator visitation modifies plant-plant interactions for pollination. Oikos 123:1037-1048. https://doi.org/10.1111/oik.01268

Macior LW (1978) Pollination Ecology of Vernal Angiosperms. Oikos 30:452-460. https://doi.org/ $\underline{10.2307 / 3543340}$

Macior LW (1973) The Pollination Ecology of Pedicularis on Mount Rainier. American Journal of Botany 60:863871. https://doi.org/10.2307/2441066

Macior LW (1970) The Pollination Ecology of Pedicularis in Colorado. American Journal of Botany 57:716-728. https://doi.org/10.2307/2441296

Montgomery BR, Phillips CW (2015) Breeding system of Linum rigidum and effect of heterospecific pollen from introduced Euphorbia esula. Journal of Pollination Ecology 16: $\quad$ https://doi.org/10.26786/1920-7603 (2015)13

O'Brien MH (1980) The Pollination Biology of a Pavement Plain: Pollinator Visitation Patterns. Oecologia 47:213-218

Ollerton J, Winfree R, Tarrant S (2011) How many flowering plants are pollinated by animals? Oikos 120:321-326. https://doi.org/10.1111/j.1600-0706.2010. 18644.x

Orueta D (2002) Thermal Relationships Between Calendula arvensis Inflorescences and Usia Aurata Bombyliid Flies. Ecology 83:3073-3085. https://doi.org/10.1890/0012-9658(2002)083[3073: TRBCAII2.0.CO;2

Pepin N, Bradley RS, Diaz HF, et al (2015) Elevationdependent warming in mountain regions of the world. Nature Climate Change 5:424-430. https://doi.org $\not 10.1038 /$ nclimate2563

Peterson AG, Furgala B, Holdaway FG (1960) Pollination of Red Clover in Minnesota1. Journal of Economic Entomology 53:546-550. ․ https://doi.org/10.1093 〈jee/53.4.546

Roberts HF, Freeman GF (1908) Alfalfa Breeding: Materials and Methods. Kansas State Agricultural College, Agricultural Experiment Station

Thorp RW, Estes JR (1975) Intrafloral Behavior of Bees on Flowers of Cassia fasciculata. Journal of the Kansas Entomological Society 48:175-184

Young AM (1983) Seasonal Differences in Abundance and Distribution of Cocoa-Pollinating Midges in Relation to Flowering and Fruit Set Between Shaded and Sunny Habitats of the La Lola Cocoa Farm in Costa Rica. Journal of Applied Ecology 20:801-831. https://doi.org/10.2307/2403127 
Wainwright SA (2013) Axis and Circumference. Harvard University Press

Whitaker DL, Webster LA, Edwards J (2007) The biomechanics of Cornus canadensis stamens are ideal for catapulting pollen vertically. Functional Ecology
21:219-225. https://doi.org/10.1111/j.1365-2435.2007. 01249.x

Whitney GG (1984) The Reproductive Biology of Raspberries and Plant-Pollinator Community Structure. American Journal of Botany 71:887-894. https://doi.org/10.2307/2443659

This work is licensed under a Creative Commons Attribution 3.0 License. 